\title{
Council 1986
}

Following the Seminar on International Research Facilities (p. 60) and meetings of the Executive Committee, the Education Committee, the Finance Committee, the Physics and Society Committee, the Publications Committee and the Board of the Interdivisional Group for Physics Development, Council assembled at the headquarters of The Institute of Physics in London on 20/21 March 1986. A great deal of business was accomplished, the scope corresponding to the ever-widening activities of the Society. In the account which follows we summarise just some of the discussions that took place.

\section{Advisory Committees}

The retiring President, Prof. G.H. Stafford opened his report by reviewing the work of the Advisory Committees. There is a feeling that we have still not found the key to making the Committee on Applied Physics and Physics in Industry (ACAPPI) really effective because although it seemed in Berlin that an active programme had been worked out with the delegates of the Associate Members, little had subsequently transpired. However, the plans for organising specialised workshops of a largely interdisciplinary nature, on topics of current industrial interest, were now maturing and the first would be held in Bad Honnef in April 1987 on Low Resolution Pyroelectric Arrays. In any case, a low reaction coefficient among the Associate Members was not necessarily a sign of dissatisfaction.

The approving and sponsoring of meetings (even if our terminology is not always understood) continues at a steady rate; the Conference Committee last year accepted 9 approved (i.e. EPS organized) and 25 sponsored conferences plus 11 schools of which 3 were EPS organized and 4 study conferences. In consultation with the Divisions new guide-lines are being drawn up for EPS conferences that should help the organizers and provide a more consistent framework.

In Physics Education attention is focussed on inaugurating a series of international study conferences which will bring together those undertaking research on physics education and those concerned with training teachers. A wide interaction with other similar groups such as the IUPAP Commission, the Groupe International de Recherche sur l'Enseignement de la Physique, and the American Association of Physics Teachers is also being pursued.

The Physics and Society Committee has latterly been concentrating on two specific activities: a restricted workshop on the "Scientific Aspects of a Nuclear Winter" that will be held in Geneva in October 1986; a symposium on the Employment of Physicists in Europe to be held later that month in Bad Honnef. Reports on these will be presented at the General Conference in Helsinki in August next year.

The recommendation of the Publications Committee last year that the Europhysics label should be withdrawn from December 1987 and the EPS logo reserved for EPS publications was finally agreed by the Executive Committee. Since then thought has been given to devising alternative ways of cementing the relations between EPS and the editors and publishers of physics publications in Europe. Preliminary proposals have been put to the Executive Committee and will be discussed further with a view to establishing a definite scheme well before the label expires.

Especially arduous is the work of the Finance Committee facing the permanent problem of the non-paying IOMs (over 30\% in 1985) and the need to push recruitment. During this year the computerisation of the membership list should simplify the posting of reminders, but this would not solve the current overload on the Secretariat. Council accepted the need for a staff increase with the consequent rise in costs which could not be taken care of by the modest surplus forecast for 1986 . This meant that new sources of income must be found and increasing the membership was a top priority.

\section{DIVISIONS}

The London Council meeting was notable in having the Chairman of every Division and Inter-divisional Group present and they were much in evidence during the discussions. In the past, one had heard complaints that the Society was too dominated by the national societies, but this was certainly not the case on this occasion. The Divisions and the delegates of the IOMs and Associate Members were the principal contributors to all the debates.

In the summary which follows we shall assume that readers are already familiar with the highly successful Divisional conferences that are now a regular feature of the calendar, and we shall only touch on other aspects.

One of the main goals of the Astronomy and Astrophysics Division is to form a European Astronomical Society out of the separate national societies, following which the intention would be to become a Group Member 4b) of EPS (like the Ampère Group). Some concern was expressed that this would have the effect of widening the gap between physics and astronomy at a time when a closer relation was being sought. For the majority however, the long tradition and importance of astronomical societies and the distinctive nature of the science with its wide and valuable amateur component, pointed to a Group Membership as being the most appropriate. In any case, the standing of the Division and Section need not be affected.

Publishing was elsewhere to the fore. The Atomic and Molecular Physics Division, responding to the great new surge in activity in the field is planning a Who's Who that will be a welcome addition to the literature. The three-volume Handbook prepared by the Computational Physics Group on Formulae \& Methods in Experimental Data Evaluation has sold well - copies can still be obtained from the Secretariat (price SFR 39.- to IOMs; SFR 50.- to others). The Condensed Matter Division, where F. Bassani is taking over the chair from $\mathrm{J}$. Devreese, is negotiating for the proceedings of its general conferences to be published as a series, starting with either the Pisa conference next year or the Budapest conference in 1988. The Plasma Physics Division now has a regular newsletter published with Plasma Physics and Controlled Fusion, which also publishes the proceedings of its $\mathrm{Di}$ visional conferences while the Quantum Electronics Division, going on from its own Who's Who, has accepted an offer from Applied Physics $B$, to publish notes on European activities in its field.

The announcement by the High Energy and Particle Physics Division of the 
substantial surplus made on the Bari conference and the transfer of the majority to the EPS central funds was greeted with applause, but also provoked questions regarding the propriety of its policy on fees. It then transpired that conference fees constituted less than half the income to the conference and it was the generosity of the Italian government that had allowed such an excellent result.

In physics generally, the trend is to minimise conference fees at the expense of society membership fees, whereas in engineering the reverse is the case. With the EPS, one had the ironic situation that whereas much of the order in the conference calendar and even the very existence of some of the main conferences was due to its influence, the majority of participants (not being (OMs) paid nothing towards the costs implicit in the overall administration. There was much support for the idea that there should be a real differential between IOM and other fees and that the difference should revert to EPS automatically. There are, nevertheless, pockets of resistance to even the existence of a differential from organisers who are fearful of having a few less participants as a consequence of the higher fee implied. The Executive Committee will be studying this question anew in the light of the opinions expressed.

In the past, HEPP conferences have been essentially confined to the physics resulting from the use of accelerators but papers on accelerator physics were included in Bari and plans are now being made for a biennial conference on accelerators (of high and low energies) starting off in 1988. As noted in the report on the London Seminar, the search for new acceleration techniques is assuming a growing importance and HEPP would like to stimulate contact between the Divisions on this subject. The Nuclear Physics Division has similar interests and, as also noted in the report, there is a strong movement to try and establish cooperative projects with the high energy physicists and to gain access to their facilities.

Still to be resolved is the somewhat confusing position in the optics fields where different organisations are intent on running conferences in Europe and the overlap with engineering adds a further complexity. The aim of the Optics Division is not to separate the two disciplines but rather to ensure an effective interchange and a coherent distribution of topics between different meetings. To this end talks are being held with SPIE for example. It is also important to pur- sue an active collaboration with the Quantum Electronics Division which in its turn has an established exchange with the Optical Society of America.

A lively interest was shown in the growing activities of the Inter-Divisional Group on Physics for Development (EUrophys. News, Feb. 1986, p. 30) which everyone hopes will make a real contribution to physics in the less endowed countries, despite the intrinsic difficulties of making a real impact.

Council approved the Executive Committee's recommendation that a new Inter-Divisional Group on Experimental Physics Control Systems should be set up within the EPS (see page 72). Questions were asked on whether this might not be part of the Computational Physics Group, but the scope envisaged is much broader than this would suggest. The study that had been undertaken had revealed a widespread interest amongst the leading physics institutions where it was recognised that parallel developments were going on that should be drawn together. Two distinct views were apparent: those who wished to limit the number of different specialist bodies and those who believed that EPS should foster the formation of such bodies, allowing that they need not have a permanent existence. The prevailing argument was that here was a dynamic group of physicists, keen to work together under the EPS umbrella, and they should therefore be encouraged. We should review in two year's time whether the inter-divisional structure was indeed the best formula.

\section{Europhysics Letters}

General satisfaction was expressed at the way Europhysics Letters had got off the ground although one could not yet be completely content with the subject distribution nor the geographic distribution of authors. It was no doubt to be expected that initially French and Italian authors would be prominent, as the new journal was a development out of their own traditional outlets, and that condensed matter physics should be so well featured as this was the largest sector of physics today ( $c f$ the strength of the different EPS Divisions). Nevertheless, an effort was needed to promote the journal in other sectors of physics, notably at Divisional conferences, and also attract contributions from those countries, in particular the UK, that were under-represented.

\section{Evening Lecture}

After the first session of Council, delegates were treated to an infectiously zestful lecture from Professor R. Mössbauer on the Rest-mass of the Neutrinos. His beautifully clear survey of the different approaches to the mass determination and, in particular, those at his own laboratory, contained a provocative message to the experimentalists to keep their attention on their instruments and leave speculation to the theorists who could always explain any number that came up! On this note, Council returned to the headquarters of our hosts, The Institute of Physics for a highly successful gastronomic experiment offered by the Institute.

\section{BUREAU INTERNATIONAL
DES POIDS ET MESURES}

\section{vacancy for a PHYSICIST}

The Bureau International des Poids et Mesures (BIPM) has a vacancy for a physicist having a wide knowledge and experience of the application of micro-computers to laboratory experiments. He or she should have a Ph.D. or equivalent, a good mathematical ability and experience in writing and implementing software (at least in Fortran, Basic and assembly languages) and will be expected to give advice on computing problems in all areas of BIPM activity (see Profile of BIPM, J. Phys. E, 1985, 18, 368-371). In addition the person appointed will be expected to take an active part in work in one of the following areas: optics (lasers as wavelength and frequency standards, interferometry), mechanics (development of servo-controlled balances, studies of surface effects on mass standards) or radiometry. It is envisaged that after an initial period of up 2 years depending upon the candidate's previous experience, the appointment will be made permanent.

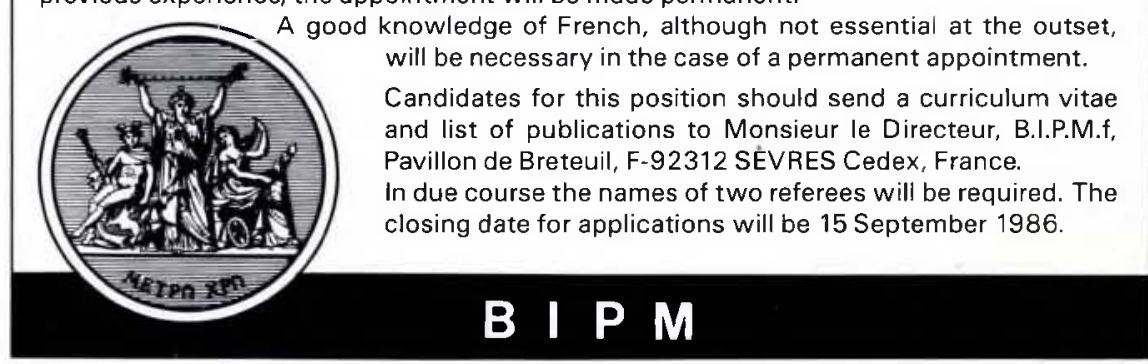

